Drug Alcohol Depend. 2019 June 01; 199: 106-115. doi:10.1016/j.drugalcdep.2019.02.020.

\title{
Self-Administration of Edible $\Delta^{9}$-Tetrahydrocannabinol and Associated Behavioral Effects in Mice.
}

\author{
Michael P. Smoker ${ }^{a,}{ }^{,}$, Ken Mackie ${ }^{b}$, Christopher C. Lapish ${ }^{a}$, Stephen L. Boehm II \\ aDepartment of Psychology and Indiana Alcohol Research Center, Indiana University - Purdue \\ University Indianapolis, Indianapolis, IN 46202 \\ ${ }^{b}$ Department of Psychological and Brain Sciences and the Gill Center, Indiana University \\ Bloomington, Bloomington, IN 47405
}

\section{Abstract}

Background: With increasing access to legal cannabis across the globe, it is imperative to more closely study its behavioral and physiological effects. Furthermore, with the proliferation of cannabis use, modes of consumption are changing, with edible formulations becoming increasingly popular. Nevertheless, there are relatively few animal models of self-administration of the primary psychoactive component of cannabis, $\Delta^{9}$-tetrahydrocannabinol (THC), and almost all incorporate routes of administration other than those used by humans. The aim of the current study was to develop a model of edible THC self-administration and assess its impact on CB1 receptormediated behaviors in female and male mice.

Methods: Mice were given limited access to a palatable dough which occasionally contained THC in doses ranging from 1 to $10 \mathrm{mg} / \mathrm{kg}$. Following dough consumption, mice were assessed for home cage locomotor activity, body temperature, or analgesia. Locomotor activity was also assessed in conjunction with the CB1 receptor antagonist SR141716A.

Results: Dough was well-consumed, but consumption decreased at the highest THC concentrations. Edible THC produced dose-dependent decreases in locomotor activity and body temperature in both sexes, and these effects were more pronounced in male mice. Hypolocomotion induced by edible THC was attenuated by SR141716A, indicating mediation by CB1 receptor activation.

Conclusions: In contrast to other cannabinoid self-administration models, edible THC is relatively low in stress and uses a route of administration analogous to one used by humans. Potential applications include chronic THC self-administration, determining THC reward/ reinforcement, and investigating consequences of oral THC use.

\section{Keywords}

Cannabinoid; Edible; Oral; Self-Administration; Sex Difference; $\Delta^{9}$-Tetrahydrocannabinol

*Corresponding Author: Michael P. Smoker, Department of Psychology, Indiana University - Purdue University Indianapolis, $402 \mathrm{~N}$ Blackford St, LD 124, Indianapolis, IN 46202, Phone: 317-429-7023, Fax: 317-274-6756, msmoker@iupui.edu. 


\section{Introduction}

Cannabis has been used by humans for centuries (Russo, 2007), and in the United States, cannabis and cannabis preparations are the most frequently used illicit drugs among adolescents and young adults (Schulenberg et al., 2017). Although the cannabis plant contains numerous phytocannabinoids, its psychoactive effects are primarily due to $\Delta^{9}$ tetrahydrocannabinol (THC) (Grotenhermen, 2003; Ranganathan and D'Souza, 2006). Recently there has been a trend towards legalization for both medicinal and recreational purposes, leading to an abundance of cannabis-based products, many of which are relatively high in THC concentration compared to cannabis plant material. A particular area of interest is the increase in popularity of THC edibles, especially given evidence that this route of administration can elicit extreme, adverse reactions (Benjamin and Fossler, 2016; Bui et al., 2015; Favrat et al., 2005; Monte et al., 2015).

Human research into the effects of cannabis use is limited by both ethical barriers and a lack of control over subjects' prior exposure to cannabis and other drugs. Therefore, animal models of cannabis administration are extremely valuable for the well-controlled investigation of behavioral and physiological causes and consequences of cannabis use. However, self-administration of cannabinoids in animals has been notoriously difficult to establish (Justinova et al., 2005; Melis et al., 2017; Panagis et al., 2008; Tanda and Goldberg, 2003; Wakeford et al., 2017). Animal studies successfully demonstrating cannabinoid self-administration typically use intravenous delivery (Justinova et al., 2003; Melis et al., 2017; Spencer et al., 2018; Wakeford et al., 2017), a route not used by humans and one requiring invasive surgery. Moreover, successful intravenous self-administration often involves food deprivation, restraint, and/or prior exposure to experimenteradministered cannabinoids (Fattore et al., 2001; Justinova et al., 2003; Martellotta et al., 1998; Melis et al., 2017; Spencer et al., 2018; Wakeford et al., 2017). Conversely, experimenter administration of cannabinoids has several drawbacks, including the stress associated with administration, routes of administration not used by humans, and its involuntary nature. Considering the increase in oral use of THC by humans and the limitations of current animal models, two recent studies have had explored oral selfadministration of THC in rats using cookies (Nelson et al., 2018) or sweetened solutions (Barrus et al., 2018). In this study, we sought to develop a mouse model of THC selfadministration with the following aims: voluntary oral self-administration in mice of a behaviorally-effective dose(s), repeated self-administration of a behaviorally-effective dose(s), and CB1 receptor mediation of behavioral effects. We also sought to explore potential sex differences using this model.

\section{Methods}

\subsection{Animals}

C57BL/6J (B6) mice were obtained from Jackson Laboratory (Bar Harbor, ME) at 7-8 weeks of age, and experimentation began at 8-9 weeks of age. All mice had ad libitum access to food and water for the duration of the experiment, except for the dough access period (see procedure). Mice were single-housed (Experiments 1 and 3) or pair-housed (Experiment 2) under a 12-hour, reverse light/dark schedule in temperature- and humidity-

Drug Alcohol Depend. Author manuscript; available in PMC 2020 June 01. 
controlled rooms. Procedures were approved by the IUPUI School of Science Institutional Animal Care and Use Committee and conformed to the Guide for the Care and Use of Laboratory Animals (The National Academic Press, 2003).

\subsection{Drugs}

THC was provided by the National Institute on Drug Abuse (Bethesda, MD) dissolved in $95 \%$ ethanol at a concentration of $100 \mathrm{mg} / \mathrm{ml}$. SR141716A (Rimonabant) was purchased from Cayman Chemical (Ann Arbor, MI) and dissolved in 100\% ethanol at a concentration of $20 \mathrm{mg} / \mathrm{ml}$. The SR141716A-ethanol solution was mixed in a vehicle of Tween-20 and saline in a ratio of 1:1:18. The control vehicle contained an equal amount of ethanol without SR141716A.

\subsection{Edible Dough}

Edible dough consisted of flour, sugar, salt, and glycerol (all commercially available). A unique batch of dough was prepared daily for each THC dose to be provided, from which individual servings (5 mg per $1 \mathrm{~g}$ of body weight) were portioned per mouse. Mice were moved individually from their home cage to an empty cage containing a single dough serving at 1 hour into the dark portion of the light/dark cycle, and allowed to consume dough for 180 minutes (day 1, Experiments 1-3), 90 minutes (day 2, Experiments 1-2), 60 minutes (day 2, Experiment 3), or 30 minutes (all other days). Details of dough preparation and access are provided in figure $\mathrm{S} 1^{1}$.

\subsection{Experiment 1}

The impact of gradually-increasing (Fade) doses or a fixed (No Fade) dose of edible THC on locomotor activity was assessed within subjects in single-housed mice. Mice were randomly assigned to either the THC Fade or No Fade condition (female $(\mathrm{n}=8)$ and male $(\mathrm{n}=8)$ per condition). Following 4 days of introduction to control dough, mice in the Fade condition were given alternating access to control and THC dough, with THC dose increasing across access periods $(1,1,2,2,5,5,5 \mathrm{mg} / \mathrm{kg})$. Mice in the No Fade condition continued to receive access to control dough until a behaviorally effective dose (i.e. $5 \mathrm{mg} / \mathrm{kg}$ ) was found in Fade mice. Timelines of daily dough/dose available and amount of dough consumed in each condition for both female and male mice are provided in figures $1 \mathrm{~A}-\mathrm{B}$ and $2 \mathrm{~A}-\mathrm{B}$, respectively. Immediately following dough access, mice were returned to their home cages, and locomotor activity was recorded for the following 23 hours. Details on the activity monitors used (Columbus Instruments Inc., Columbus, $\mathrm{OH}$ ) have been previously published (Linsenbardt and Boehm, 2012). On the final day of testing, all mice were given access to 10 $\mathrm{mg} / \mathrm{kg}$ THC dough. Immediately following dough access and prior to replacement in the home cage, mice were administered the CB1 receptor antagonist, SR141716A (10 mg/kg), or vehicle at a volume of $0.01 \mathrm{ml} / \mathrm{g}$ (i.p.). For Experiment 1, for each THC dose, control dough activity was averaged per mouse across proximal days (e.g. days 5, 9, $11(1 \mathrm{mg} / \mathrm{kg})$ ). For SR141716A/vehicle assessment, mice were split into low- (THC $<4 \mathrm{mg} / \mathrm{kg}$ ) and high(THC $>4 \mathrm{mg} / \mathrm{kg}$ ) consuming groups. Daily activity, relative activity (\% of proximal

\footnotetext{
${ }^{1}$ Supplementary material can be found by accessing the online version of this paper at http://dx.doi.org and by entering doi:
} 
control), dose x activity relationships, and relative activity following SR141716A/vehicle treatment were analyzed using repeated measures two-way ANOVAs followed by Bonferroni-corrected t-tests, Wilcoxon signed rank tests, Pearson correlations, and independent-samples t-tests, respectively.

\subsection{Experiment 2}

The impact of gradually-increasing (Fade) doses of edible THC on body temperature was assessed within subjects in pair-housed mice. Subsequently, the impact of a larger edible THC dose on analgesia was assessed between subjects. Mice (female $(\mathrm{n}=8)$, male $(\mathrm{n}=8)$ ) were assigned to the Fade condition as described in Experiment 1, with the exception of 2, instead of 3, days of access to $5 \mathrm{mg} / \mathrm{kg}$ THC dough. Timelines of daily dough/dose available and amount of dough consumed for both female and male mice are provided in figures $1 \mathrm{C}$ and $2 \mathrm{C}$, respectively. Rectal temperature $\left({ }^{\circ} \mathrm{C}\right)$ of mice was assessed at 1 hour postconsumption on control dough days and at 30 minutes, 1 hour, and 2 hours postconsumption on THC dough days. Temperature was measured using a thermometer (Physitemp Instruments, Inc., Clifton, NJ) equipped with a mouse rectal probe (Braintree Scientific, Inc., Braintree, MA). On the final day of testing, mice were given access to control or $10 \mathrm{mg} / \mathrm{kg}$ THC dough and assessed for analgesia. Mice were set in a glass beaker on a hot plate at $55.8 \pm 0.2{ }^{\circ} \mathrm{C}$ and immediately removed at the first pain response, jump or paw lick, or after a maximum latency of 25 seconds. Both the hot plate temperature and maximum latency used were within the range of previously reported values (Schreiber et al., 1999; Welch and Stevens, 1992). Analgesia was assessed on consecutive days, 1 hour after control dough access on the first day (pre-treatment) and then 1 and 2 hours after control or $10 \mathrm{mg} / \mathrm{kg}$ THC dough access on the second day (post-treatment). Analgesia was determined as the percent maximum possible effect (\% MPE) using the formula \% MPE $=(($ posttreatment latency - pre-treatment latency) / (maximum latency - pre-treatment latency)) $\mathrm{x}$ 100, as previously published (Schreiber et al., 1999; Welch and Stevens, 1992). For Experiment 2, temperature at 60 minutes post-consumption on the preceding control dough day was subtracted from temperatures at 30,60, and 120 minutes post-consumption on each THC dough day. Within each dose, these temperature differences were collapsed across time points and days, as they did not differ significantly based on time point or day for either female, $F \mathrm{~s}<2.51, p$ 's $>.116$, or male, $F \mathrm{~s}<3.65, p$ 's $>.053$, mice. Due to technical issues with the temperature probe, only the first day at $5 \mathrm{mg} / \mathrm{kg}$ was included. Temperature differences were analyzed using one-sample t-tests $\left(v s 0^{\circ} \mathrm{C}\right)$ as well as Pearson correlations. The effect of edible THC on analgesia was analyzed using repeated measures two-way ANOVAs on \%MPE.

\subsection{Experiment 3}

The impact of a fixed (No Fade) dose of edible THC on body temperature was assessed between subjects in single-housed mice (female $(n=24)$, male $(n=24)$ ). 6 days of access to control dough preceded a single test day of access to control, $5 \mathrm{mg} / \mathrm{kg}$, or $10 \mathrm{mg} / \mathrm{kg}$ THC dough (n's $=6,6,12$, respectively per sex). Timelines of daily dough/dose available and amount of dough consumed for both female and male mice are provided in figures 1D and 2D, respectively. Mice were assessed for rectal temperature (as in Experiment 2) at 2 hours post-consumption on the final control dough day and at 1 and 2 hours post-consumption on 
test day. All female mice, and a randomly-selected subset of male mice $(n=6)$ with access to $10 \mathrm{mg} / \mathrm{kg}$ THC dough, were additionally assessed for rectal temperature at 4 and 24 hours post-consumption. For Experiment 3, mice were split into control, low- (THC $<5 \mathrm{mg} / \mathrm{kg}$ ), and high- (THC $\geq 5 \mathrm{mg} / \mathrm{kg}$ ) consuming groups. Temperature at 2 hours post-consumption on the preceding control dough day was subtracted from temperatures at 1,2, 4, and 24 hours post-consumption on test day and analyzed using repeated measures two-way ANOVAs followed by Bonferroni-corrected t-tests, one-sample t-tests, and Pearson correlations.

\subsection{Statistical Analysis}

Statistical analysis was conducted in GraphPad Prism 5 (GraphPad Software Inc., La Jolla, $\mathrm{CA}$ ), with significance set at $p<.05$. Female and male mice were considered separately, except where noted. Consumption (\% of dough consumed) was analyzed separately for each experiment and condition (Fade vs No Fade) using Wilcoxon signed rank tests (vs 100\%). Analyses of individual experiments are described above.

\section{Results}

\subsection{Consumption}

In female mice, dough was consumed at significantly less than $100 \%$ in the Fade condition at $5 \mathrm{mg} / \mathrm{kg}, W=-21, p=.031$ (Experiment 1; Fig. 1A; Table 1), and in the No Fade condition at control, $W=-136, p<.001$, and $10 \mathrm{mg} / \mathrm{kg}, W=-45, p=.004$ (Experiment 3; Fig. 1D; Table 1). In male mice, dough was consumed at significantly less than $100 \%$ in the Fade condition at $5 \mathrm{mg} / \mathrm{kg}, W=-21, p=.031$, and $10 \mathrm{mg} / \mathrm{kg}, W=-28, p=.016$ (Experiment 1; Fig. 2A; Table 1), and in the No Fade condition at $10 \mathrm{mg} / \mathrm{kg}, W=-66, p$ $=.001$ (Experiment 3; Fig. 2D; Table 1). In all other instances in both sexes, consumption of dough did not differ significantly from $100 \%, W \mathrm{~s}>-15, p$ 's $>.058$ (Figs. 1A-D, 2A-D; Table 1). Lastly, consumption of dough on the final day of Experiment 2 was not analyzed, as mice were split into control and $10 \mathrm{mg} / \mathrm{kg}$ groups systematically, based on prior consumption levels.

\subsection{Experiment 1}

Daily locomotor activity following consumption of THC dough was compared to that following consumption of control dough in 30-minute bins across 8 hours for female and male mice in both conditions (Fade and No Fade). In female Fade mice, there was a main effect of time on all days, $F \mathrm{~s}>9.40, p$ 's $<.003$ (Figs. 3A-C), and an interaction between time and THC dose at $1 \mathrm{mg} / \mathrm{kg}$ on day $10, F(15,210)=6.75, p=.007$ (Fig. 3A). There was a trend towards a main effect of THC dose at $2 \mathrm{mg} / \mathrm{kg}$ on day $12, F(1,14)=5.21, p=.057$ (Fig. 3B), and a significant main effect of THC dose at $5 \mathrm{mg} / \mathrm{kg}$ on day $22, F(1,14)=4.25, p$ $=.034$ (Fig. $3 \mathrm{C}$ ), with THC dough decreasing locomotor activity vs control dough. In female No Fade mice, one mouse was excluded as an outlier with consistently elevated activity, and interestingly at the $5 \mathrm{mg} / \mathrm{kg}$ THC dose, there was a main effect of time, $F(15,180)=7.16, p$ $=.038$, but no main effect of THC dose or interaction, $p$ 's $>.317$ (Fig. 3D). In male Fade mice, there was also a main effect of time on all days, $F \mathrm{~s}>36.56, p$ 's $<.001$ (Figs. $4 \mathrm{~A}-\mathrm{C}$ ). At $5 \mathrm{mg} / \mathrm{kg}$, there was both a main effect of THC dose and interaction between time and THC dose on day $18, F \mathrm{~s}>5.44, p$ s $<.015$, with THC significantly decreasing activity at 
$60,90,120$, and 180 minutes post-consumption, $p$ 's $<.05$, as well as a trend towards a main effect of THC dose on days 22 and 24, $F$ s $>2.60$, $p$ 's <.068 (Fig. 4C). In male No Fade mice, all effects were significant at $5 \mathrm{mg} / \mathrm{kg}$ on day $24, F \mathrm{~s}>11.96, p$ 's $<.001$, with robust decreases in activity following consumption of THC dough vs control dough for the first 150 minutes following consumption, $p$ 's $<.001$ (Fig. 4D).

To compare sexes, the effect of edible THC on relative locomotor activity (\% of proximal control dough days) was also assessed, collapsed on days within each THC dose, using expanded temporal windows (2-hour bins), and using only mice consuming $\geq 50 \%$ of the dose provided. There was no effect in either sex at the $1 \mathrm{mg} / \mathrm{kg}$ dose, $p$ 's $>.127$ (Fig. 5A). At the $2 \mathrm{mg} / \mathrm{kg}$ dose, edible THC decreased activity in female mice at all time points except 3-4 hours post-consumption, $W$ s $<-81$, p's $<.019$; however, there was no effect in male mice, $p$ 's $>.365$ (Fig. 5B). In Fade mice at $5 \mathrm{mg} / \mathrm{kg}$, edible THC decreased activity in both sexes, lasting 6 hours in female mice, $W^{\prime} \mathrm{s}<-154$, p's $<.013$, and lasting all 8 hours in male mice, $W \mathrm{~s}<-136$, p's $<.033$ (Fig. 5C). In No Fade mice at $5 \mathrm{mg} / \mathrm{kg}$, edible THC decreased activity in both sexes, lasting 2 hours in female mice, $W=-24, \mathrm{p}=.047$, and lasting 4 hours in male mice, $W^{\prime} \mathrm{s}<-35$, p's $<.008$ (Fig 5D).

In support of THC being responsible for decreases in locomotor activity, THC dose consumed was significantly negatively associated with relative activity in both sexes, and this relationship was more pronounced in male mice (Table 2). In support of CB1 receptors mediating the effect of edible THC on locomotor activity, combining sexes and conditions for hours 1-4 post-consumption on day $33(10 \mathrm{mg} / \mathrm{kg})$, there was a significant negative relationship between dose consumed and relative activity following vehicle, $r(16)=-.50, p$ $=.0498$ (Fig. 6A; Table 2), but not SR141716A, $r(16)=-.26, p=.321$ (Fig. 6B; Table 2), post-treatment. Accordingly, high-consuming mice showed reduced relative activity compared to low-consuming mice following vehicle post-treatment only, $t(14)=2.60, p$ $=.021$ (Fig. 6C).

\subsection{Experiment 2}

The effect of edible THC on both body temperature and analgesia was examined in pairhoused mice of both sexes. In female mice, there was no effect of THC on body temperature for any dose, $p$ 's $>.184$ (Fig. 7A) and no relationship between dose consumed and temperature difference, $p=.252$ (Table 2). In male mice, there was a trend towards an effect of THC on body temperature at the $5 \mathrm{mg} / \mathrm{kg}$ dose, $t(7)=2.31, p=.054$ (Fig. 7B), but no effect at lower doses, $p$ 's $>$.388. In addition, there was a significant negative relationship between THC dose consumed and temperature difference, $r(40)=-.34, p=.032$ (Table 2). Regarding analgesia, there was no effect of THC or time point, nor an interaction on \% MPE in either sex, $p$ 's > .118 (Fig. 7C).

\subsection{Experiment 3}

Experiment 2 revealed no effect of edible THC on analgesia, and a subtle effect of edible THC on body temperature at $5 \mathrm{mg} / \mathrm{kg}$, only in male mice. Given that these mice had multiple exposures to THC, potentially inducing some degree of tolerance, the effect of a single acute exposure to edible THC at doses up to $10 \mathrm{mg} / \mathrm{kg}$ on body temperature was assessed in

Drug Alcohol Depend. Author manuscript; available in PMC 2020 June 01. 
Experiment 3. Mice were separated into groups based on test day consumption, control dough, THC dough $<5 \mathrm{mg} / \mathrm{kg}$, and THC dough $\geq 5 \mathrm{mg} / \mathrm{kg}$. These groups did not differ in baseline body temperature following consumption of control dough on the preceding day, $F(2,42)=.14, p=.871$, but a sex difference was present, $F(1,42)=153.50, p<.001$ (Fig. 7D). On test day, in female and male mice, there was a main effect of dose, $F(2,63)=4.71$, $p=.021$ and $F(2,21)=5.01, p=.017$, respectively, with high-consuming mice differing from control at the 1 hour time point, $p$ 's $<.01$ (Figs. 7E-F). High-consuming male mice and both low- and high-consuming female mice, but not control, showed a non-zero change in temperature at multiple time points, $t$ s $>2.54, p$ 's $<.027$ (Fig. 7E-F). In support of THC being responsible for reductions in temperature, THC dose consumed was significantly negatively associated with change in temperature at both the 1- and 2-hour time points in both sexes, $p$ 's $<.009$ (Table 2).

\section{Discussion}

Mice consumed control dough relatively consistently, and THC dough was well-consumed, with some reduction at higher doses. Nevertheless, mice consumed THC dough on multiple occasions across a range of doses, and multiple mice consumed $100 \%$ of THC dough up to $10 \mathrm{mg} / \mathrm{kg}$. Thus, edible THC provides a translationally-valid route of self-administration in mice. Edible THC produced dose-dependent hypolocomotion lasting multiple hours in both sexes, an effect attenuated by the CB1 receptor antagonist SR141716A. Additionally, THC had a modest hypothermic effect in male, but not female mice when consumed chronically (Experiment 2), and a more pronounced hypothermic effect when administered acutely (Experiment 3). However, it was not found to produce analgesia in either sex. Taken together, oral self-administration of THC reproduced some of the characteristic effects typically seen following experimenter-administered CB1 receptor agonists (Lichtman et al., 2001; Little et al., 1988; McMahon and Koek, 2007).

Although cannabinoid self-administration, including THC, has previously been demonstrated (Fattore et al., 2001; Justinova et al., 2003; Martellotta et al., 1998; Melis et al., 2017; Spencer et al., 2018; Wakeford et al., 2017), this study is among the first to do so using an oral route of administration and without food deprivation, invasive surgery, restraint, or prior cannabinoid exposure. In this respect, it is in line with demonstrations of oral THC self-administration in rats (Barrus et al., 2018; Nelson et al., 2018). However, there are notable differences among the three studies, including the species used and the method of ingestion. Perhaps most notable is the homogenous nature of the THC preparations provided in the current study and Barrus et al. (2018), which allowed for posthoc determination of dose consumed. Nevertheless, all three studies demonstrated what appears to be THC-induced conditioned taste aversion, and the current study and Nelson et al. (2018) demonstrated an effect of edible THC on CB1 receptor-mediated behaviors. As such, the use of edible THC as described here could provide some advantages over other administration methods. First, besides brief handling, mice were minimally stressed, and they showed similar THC dough consumption patterns in single-housed and group-housed arrangements (Fade - Experiment 1 vs 2). Stress associated with handling or injection is immediately measurable (Meijer et al., 2006) and can have long-lasting behavioral and physiological consequences (Renaud et al., 2015; Sandi and Haller, 2015; Torregrossa et al., 
2012). Therefore, oral self-administration could be utilized for a low-stress, chronic THC dosing paradigm.

Second, there is growing interest in understanding the consequences of oral THC administration, and while there are animal models of oral self-administration for other recreational drugs (Horowitz et al., 1977; Rhodes et al., 2005; Samson, 1986), this is among the first to report voluntary oral THC self-administration in non-human animals. For cannabinoids, the standard route of oral administration has been gavage (Anderson et al., 1975; Castañeda et al., 1991; Mantilla-Plata and Harbison, 1975; Stiglick and Kalant, 1982), which has a number of drawbacks, including stress, tissue damage, and lack of oral-mucosal drug exposure (Vandenberg et al., 2014; Zhang, 2011). For these reasons alone, the oral selfadministration procedure here presents a reasonable alternative to oral gavage, with the caveat that most mice appear unlikely to repeatedly self-administer higher doses (i.e. $\geq 10$ $\mathrm{mg} / \mathrm{kg}$ ). Furthermore, it uses a method of consumption analogous to that used in humans, namely edible THC.

Third, oral self-administration could be used to investigate the rewarding and reinforcing properties of THC. The simple fact that mice self-administered THC dough could be seen as evidence that it is rewarding. However, inspection of consumption patterns indicates that THC might have been aversive at higher doses, which is best illustrated in Experiment 1 male Fade mice on days 17-25. This consumption pattern suggests that mice can discriminate THC from control dough and that something about the $5 \mathrm{mg} / \mathrm{kg}$ dose might have been aversive for some mice, something that might be augmented by the addition of cannabidiol to THC dough (Russo and Guy, 2006; Spencer et al., 2018; Vann et al., 2008). It could also be that mice find control dough rewarding and are willing to experience the subjective effects of THC, up to a point, to consume dough. As THC and the dough itself cannot be disambiguated in this experiment, a choice or preference procedure using both control and THC dough will be beneficial in this regard. In addition, demonstration of THC's rewarding properties via conditioned place preference (CPP) has been fraught with difficulty, typically only occurring under specific parameters of dose, inter-dose interval, and prior/priming exposure (Melis et al., 2017; Panagis et al., 2008; Tanda and Goldberg, 2003). A combination of self-administration and CPP could possibly allow mice to determine (via consumption) and demonstrate (via CPP) doses of edible THC that are rewarding. Lastly, oral self-administration might be less useful than intravenous self-administration in determining the reinforcing properties of THC, as it is yet to be determined if edible THC could be delivered as reliably following response requirements and what impact the delay in onset of effects following oral administration could have. However, the reinforcing properties of access to an edible THC session could be assessed using a runway procedure (Ettenberg and Geist, 1993) or by separating response requirements from consumption (Czachowski and Samson, 1999)].

An important aim of the current study was to explore potential sex differences. With respect to consumption, subsets of female mice were somewhat inconsistent in consuming dough early in the experiment, but became more consistent over time. In addition, consumption of dough in female, but not male, mice appears to be affected by the addition of THC on the first exposure, prior to experiencing any pharmacologic effects. This particular sex 
difference is consistent with that seen for consumption of sweetened solutions upon initial addition of THC in rats (Barrus et al., 2018). Therefore, female mice might be more reserved during initial exposures to control and THC dough. With respect to the effects of THC between sexes, a few differences are worth noting. Female mice showed a THC-induced hypolocomotor response at a lower dose $(2 \mathrm{mg} / \mathrm{kg})$ than male mice, which was longer in duration than seen at higher doses. At the $5 \mathrm{mg} / \mathrm{kg}$ dose, male mice showed a more pronounced and longer lasting response than female mice, especially without prior exposure to lower doses (No Fade). In addition, male, but not female, mice showed a modest hypothermic response to edible THC at $5 \mathrm{mg} / \mathrm{kg}$ following repeated administration, while both sexes showed a long-lasting hypothermic response to acute administration $\geq 5 \mathrm{mg} / \mathrm{kg}$. Sex differences could be due to pharmacokinetics, and considering that oral administration results in more variable absorption of THC and greater synthesis of the active metabolite 11hydroxy-THC (Benjamin and Fossler, 2016; Grotenhermen, 2003; Mantilla-Plata and Harbison, 1975; Nadulski et al., 2005), a time course of THC and 11-hydroxy-THC concentrations in plasma and brain following edible THC consumption in both sexes would be valuable.

One major limitation of the current study was the use of a single, inbred mouse strain, and therefore, the generalizability of findings remains to be determined. B6 mice were chosen for their propensity for oral self-administration of psychoactive drugs (Belknap et al., 1993; Rhodes et al., 2007). However, B6 mice have been shown to be less sensitive to THCinduced hypothermia and analgesia, but not hypolocomotion, than other mouse strains (Onaivi et al., 1995), which may have contributed to the ability of edible THC to impact locomotor activity at lower doses than the other behaviors measured here. In addition, with the exception of a small subset of mice, body temperature and analgesia measures in the current study were taken in the range of 30-120 minutes post-consumption, a time frame consistent with peak plasma concentrations and peak hypothermic/analgesic effects following orally-administered THC in Swiss-Webster mice (Anderson et al., 1975; MantillaPlata and Harbison, 1975). Considering that the effects of edible THC on locomotor activity extended for several hours, our other measurements may have been taken prior to the optimal time point(s). However, peak effects on body temperature following acute exposure occurred at 1 hour post-consumption, suggesting otherwise.

In conclusion, edible THC presents a viable alternative to other administration procedures for cannabinoids in mice and could be beneficial for chronic dosing, investigations of effects of oral administration, and determining reward/reinforcement. Furthermore, preliminary sex differences in consumption and consequences of edible THC warrant further exploration.

\section{Supplementary Material}

Refer to Web version on PubMed Central for supplementary material.

\section{References}

Anderson PF, Jackson DM, Chesher GB, Malor R, 1975 Tolerance to the effects of $\Delta 9$ tetrahydrocannabinol in mice on intestinal motility, temperature and locomotor activity. Psychopharmacology (Berl) 43, 31-36.

Drug Alcohol Depend. Author manuscript; available in PMC 2020 June 01. 
Barrus DG, Lefever TW, \& Wiley JL, 2018 Evaluation of reinforcing and aversive effects of voluntary $\Delta 9$-tetrahydrocannabinol ingestion in rats. Neuropharmacology 137, 133-140. [PubMed: 29758385]

Belknap JK, Crabbe JC, Riggan J, O’Toole LA, 1993 Voluntary consumption of morphine in 15 inbred mouse strains. Psychopharmacology (Berl) 112, 352-358. [PubMed: 7871041]

Benjamin DM, Fossler MJ, 2016 Edible cannabis products: it is time for FDA oversight. The J. Clin. Pharmacol 56, 1045-1047.

Bui QM, Simpson S, Nordstrom K, 2015 Psychiatric and medical management of marijuana intoxication in the emergency department. West. J. Emerg. Med 16, 414-417. [PubMed: 25987916]

Castañeda E, Moss DE, Oddie SD, Whishaw IQ, 1991 THC does not affect striatal dopamine release: microdialysis in freely moving rats. Pharmacol. Biochem. Behav 40, 587-591. [PubMed: 1725460]

Czachowski CL, Samson HH, 1999 Breakpoint Determination and Ethanol Self-Administration Using an Across-Session Progressive Ratio Procedure in the Rat. Alcohol Clin. Exp. Res 23, 1580-1586. [PubMed: 10549988]

Ettenberg A, Geist TD, 1993 Qualitative and quantitative differences in the operant runway behavior of rats working for cocaine and heroin reinforcement. Pharmacol. Biochem. Behav 44, 191-198. [PubMed: 8430122]

Fattore L, Cossu G, Martellotta CM, Fratta W, 2001 Intravenous self-administration of the cannabinoid CB1 receptor agonist WIN55,212-2 in rats. Psychopharmacology (Berl) 156, 410-416. [PubMed: 11498718]

Favrat B, Ménétrey A, Augsburger M, Rothuizen LE, Appenzeller M, Buclin T, Pin M, Mangin P, Giroud C, 2005 Two cases of" cannabis acute psychosis" following the administration of oral cannabis. BMC Psychiatry 5, 17. [PubMed: 15804348]

Grotenhermen F, 2003 Pharmacokinetics and pharmacodynamics of cannabinoids. Clin. Pharmacokinet 42, 327-360. [PubMed: 12648025]

Horowitz GP, Whitney G, Smith JC, Stephan FK, 1977 Morphine ingestion: genetic control in mice. Psychopharmacology (Berl) 52, 119-122. [PubMed: 407595]

Justinova Z, Goldberg SR, Heishman SJ, Tanda G, 2005 Self-administration of cannabinoids by experimental animals and human marijuana smokers. Pharmacol. Biochem. Behav 81, 285-299. [PubMed: 15932767]

Justinova Z, Tanda G, Redhi GH, Goldberg SR, 2003 Self-administration of $\Delta 9$ tetrahydrocannabinol (THC) by drug naive squirrel monkeys. Psychopharmacology (Berl) 169, 135-140. [PubMed: 12827345]

Lichtman AH, Poklis JL, Poklis A, Wilson DM, Martin BR, 2001 The pharmacological activity of inhalation exposure to marijuana smoke in mice. Drug Alcohol Depend 63, 107-116. [PubMed: 11376914]

Linsenbardt DN, Boehm SL, 2012 Role of Novelty and Ethanol History in Locomotor Stimulation Induced by Binge-Like Ethanol Intake. Alcohol Clin. Exp. Res 36, 887-894. [PubMed: 22150802]

Little PJ, Compton DR, Johnson MR, Melvin LS, Martin BR, 1988 Pharmacology and stereoselectivity of structurally novel cannabinoids in mice. J. Pharmacol. Exp. Ther 247, 10461051. [PubMed: 2849657]

Mantilla-Plata B, Harbison RD, 1975 Distribution studies of [14C] delta-9 tetrahydrocannabinol in mice: Effect of vehicle, route of administration, and duration of treatment. Toxicol. Appl. Pharmacol 34, 292-300. [PubMed: 1209626]

Martellotta MC, Cossu G, Fattore L, Gessa GL, Fratta W, 1998 Self-administration of the cannabinoid receptor agonist WIN 55,212-2 in drug-naive mice. Neuroscience 85, 327-330. [PubMed: 9622233]

McMahon LR, Koek W, 2007 Differences in the relative potency of SR 141716A and AM 251 as antagonists of various in vivo effects of cannabinoid agonists in C57BL/6J mice. Eur. J. Pharmacol 569, 70-76. [PubMed: 17553486]

Meijer MK, Spruijt BM, Van Zutphen LFM, Baumans V, 2006 Effect of restraint and injection methods on heart rate and body temperature in mice. Lab Anim 40, 382-391. [PubMed: 17018209]

Melis M, Frau R, Kalivas PW, Spencer S, Chioma V, Zamberletti E, Rubino T, Parolaro D, 2017 New vistas on cannabis use disorder. Neuropharmacology 124, 62-72. [PubMed: 28373077] 
Monte AA, Zane RD, Heard KJ, 2015 The implications of marijuana legalization in Colorado. JAMA 313, 241-242. [PubMed: 25486283]

Nadulski T, Sporkert F, Schnelle M, Stadelmann AM, Roser P, Schefter T, Pragst F, 2005 Simultaneous and sensitive analysis of THC, 11-OH-THC, THC-COOH, CBD, and CBN by GC-MS in plasma after oral application of small doses of THC and cannabis extract. J. Anal. Toxicol 29, 782-789. [PubMed: 16356335]

Nelson NG, Law WX, Weingarten MJ, Carnevale LN, Das A, \& Liang NC, 2018 Combined $\Delta$ 9tetrahydrocannabinol and moderate alcohol administration: effects on ingestive behaviors in adolescent male rats. Psychopharmacology (Berl), 1-14. [PubMed: 29178009]

Onaivi ES, Chakrabarti A, Gwebu ET, Chaudhuri G, 1995 Neurobehavioral effects of $\Delta$ 9-THC and cannabinoid (CB1) receptor gene expression in mice. Behav. Brain. Res 72, 115-125. [PubMed: 8788864]

Panagis G, Vlachou S, Nomikos GG, 2008 Behavioral pharmacology of cannabinoids with a focus on preclinical models for studying reinforcing and dependence-producing properties. Curr. Drug Abuse Rev 1, 350-374. [PubMed: 19630731]

Ranganathan M, D’Souza DC, 2006 The acute effects of cannabinoids on memory in humans: a review. Psychopharmacology (Berl) 188, 425-444. [PubMed: 17019571]

Renaud SM, Pickens LR, Fountain SB, 2015 Paradoxical effects of injection stress and nicotine exposure experienced during adolescence on learning in a serial multiple choice (SMC) task in adult female rats. Neurotoxicol. Teratol 48, 40-48. [PubMed: 25527003]

Rhodes JS, Best K, Belknap JK, Finn DA, Crabbe JC, 2005 Evaluation of a simple model of ethanol drinking to intoxication in C57BL/6J mice. Physiol. Behav 84, 53-63. [PubMed: 15642607]

Rhodes JS, Ford MM, Yu CH, Brown LL, Finn DA, Garland T, Crabbe JC, 2007 Mouse inbred strain differences in ethanol drinking to intoxication. Genes Brain Behav 6, 1-18. [PubMed: 17233637]

Russo EB, 2007 History of cannabis and its preparations in saga, science, and sobriquet. Chem. Biodivers 4, 1614-1648. [PubMed: 17712811]

Russo E, Guy GW, 2006 A tale of two cannabinoids: the therapeutic rationale for combining tetrahydrocannabinol and cannabidiol. Med. Hypotheses 66, 234-246. [PubMed: 16209908]

Samson HH, 1986 Initiation of ethanol reinforcement using a sucrose-substitution procedure in foodand water-sated rats. Alcohol Clin. Exp. Res 10, 436-442. [PubMed: 3530023]

Sandi C, Haller J, 2015 Stress and the social brain: behavioural effects and neurobiological mechanisms. Nat. Rev. Neurosci 16, 290-304. [PubMed: 25891510]

Schreiber S, Backer MM, Pick CG, 1999 The antinociceptive effect of venlafaxine in mice is mediated through opioid and adrenergic mechanisms. Neurosci. Lett 273, 85-88. [PubMed: 10505622]

Schulenberg JE, Johnston LD, O’Malley PM, Bachman JG, Miech RA, Patrick ME, 2017 Monitoring the Future national survey results on drug use, 1975-2016: Volume II, College students and adults ages 19-55. Ann Arbor: Institute for Social Research, The University of Michigan.

Spencer S, Neuhofer D, Chioma VC, Garcia-Keller C, Schwartz DJ, Allen N, Scofield MD, OrtizIthier T, Kalivas PW, 2018 A Model of $\Delta$ 9-Tetrahydrocannabinol Self administration and Reinstatement That Alters Synaptic Plasticity in Nucleus Accumbens. Biol. Psychiatry 84, 601610. [PubMed: 29861097]

Stiglick A, Kalant H, 1982 Learning impairment in the radial-arm maze following prolonged cannabis treatment in rats. Psychopharmacology (Berl) 77, 117-123. [PubMed: 6289370]

Tanda G, Goldberg SR, 2003 Cannabinoids: reward, dependence, and underlying neurochemical mechanisms - a review of recent preclinical data. Psychopharmacology (Berl) 169, 115-134. [PubMed: 12827346]

Torregrossa MM, Xie M, Taylor JR, 2012 Chronic corticosterone exposure during adolescence reduces impulsive action but increases impulsive choice and sensitivity to yohimbine in male SpragueDawley rats. Neuropsychopharmacology 37, 1656-1670. [PubMed: 22334120]

Vandenberg LN, Welshons WV, vom Saal FS, Toutain PL, Myers JP, 2014 Should oral gavage be abandoned in toxicity testing of endocrine disruptors? Environ. Health 13, 46. [PubMed: 24961440] 
Vann RE, Gamage TF, Warner JA, Marshall EM, Taylor NL, Martin BR, Wiley JL, 2008 Divergent effects of cannabidiol on the discriminative stimulus and place conditioning effects of $\Delta 9$ tetrahydrocannabinol. Drug. Alcohol Depend 94, 191-198. [PubMed: 18206320]

Wakeford AG, Wetzell BB, Pomfrey RL, Clasen MM, Taylor WW, Hempel BJ, Riley AL, 2017 The effects of cannabidiol (CBD) on $\Delta^{9}$-tetrahydrocannabinol (THC) self-administration in male and female Long-Evans rats. Exp. Clin. Psychopharmacol 25, 242-248. [PubMed: 28682102]

Welch SP, Stevens DL, 1992 Antinociceptive activity of intrathecally administered cannabinoids alone, and in combination with morphine, in mice. J. Pharmacol. Exp. Ther 262, 10-18. [PubMed: 1320680]

Zhang L, 2011 Voluntary oral administration of drugs in mice. Protocol Exchange, 10. 
A

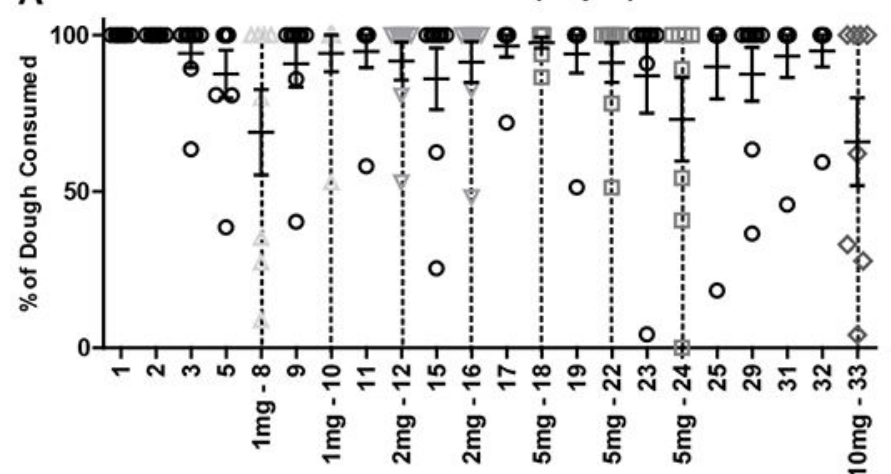

C

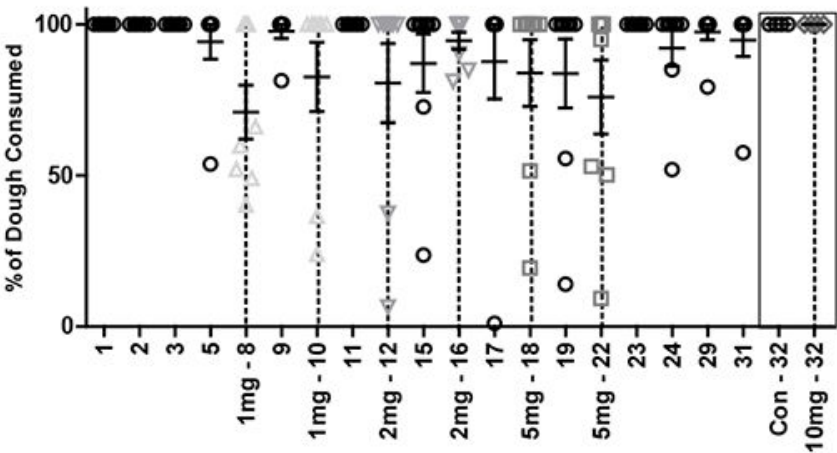

B

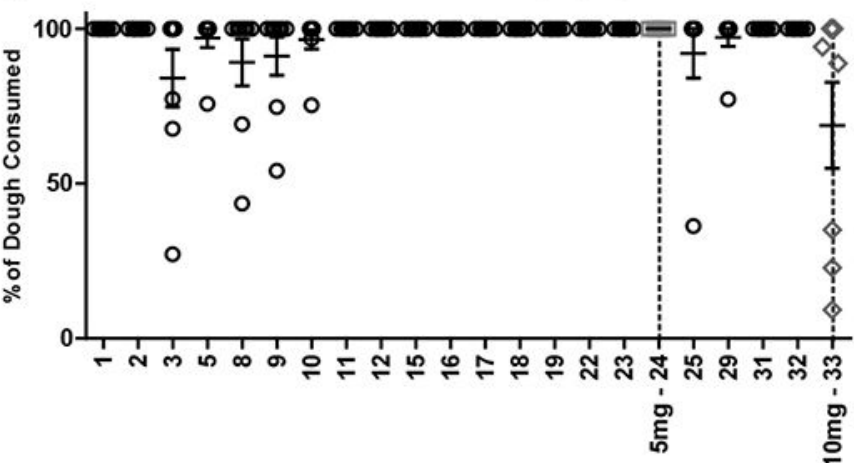

D Female - No Fade (Exp 3)

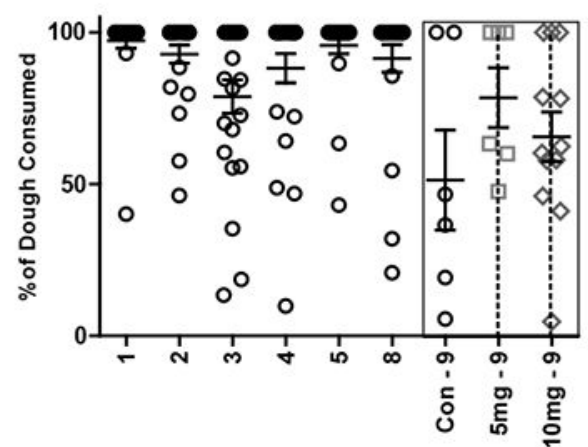

Figure 1.

Timeline and dough consumption in female mice (mean \pm SEM) for A) Experiment 1 Fade condition $(\mathrm{n}=8)$, B) Experiment 1 No Fade condition $(\mathrm{n}=8)$, C) Experiment 2 Fade condition ( $(n=8)$, and D) Experiment 3 No Fade condition (n's = 6-12). \% of dough consumed was calculated by subtracting leftover, post-consumption dough weight from initial dough serving weight. Dough access was 60-120 minutes on days 1 and 2 and 30 minutes on all other days. X-axis indicates experimental day and THC dose provided in $\mathrm{mg}$ (per kg). Black circles = control dough. Gray shapes (unique per dose) and dashed vertical lines $=$ THC dough. Black boxes in (C/D) indicate a difference in THC dose provided between subjects. 
A

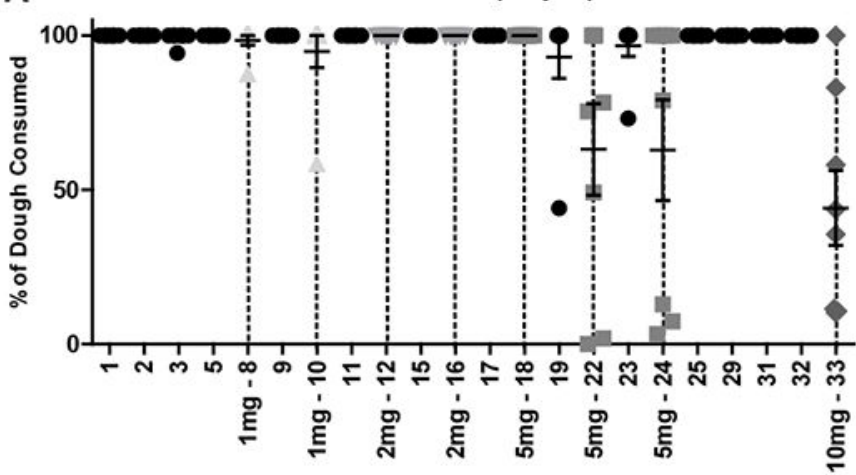

C

Male - Fade (Exp 2)

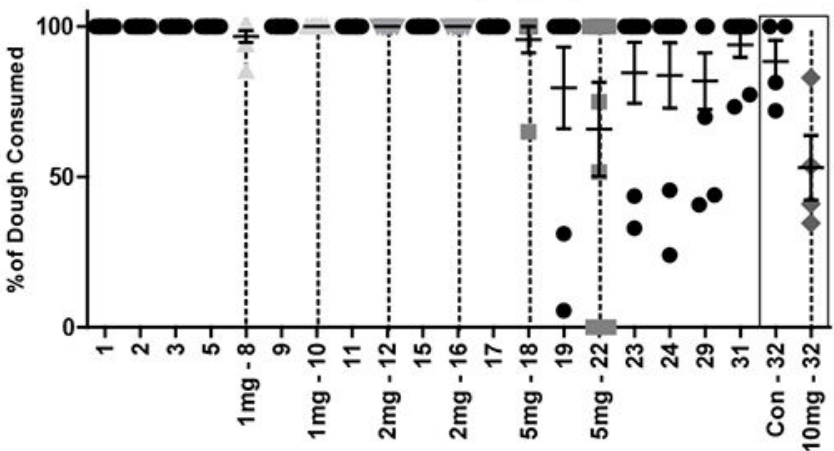

B

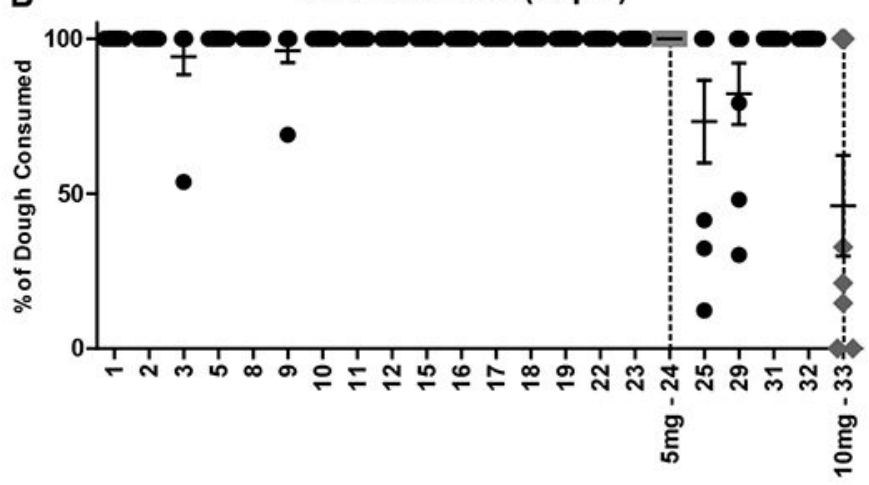

D Male - No Fade (Exp 3)

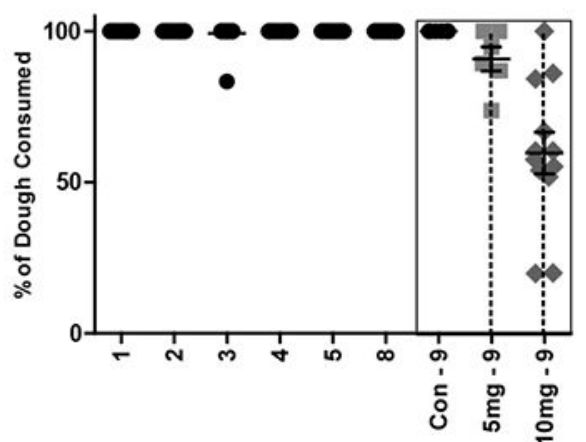

Figure 2.

Timeline and dough consumption in male mice (mean \pm SEM) for A) Experiment 1 Fade condition $(\mathrm{n}=8)$, B) Experiment 1 No Fade condition $(\mathrm{n}=8)$, C) Experiment 2 Fade condition ( $n=8)$, and D) Experiment 3 No Fade condition (n's = 6-12). \% of dough consumed was calculated by subtracting leftover, post-consumption dough weight from initial dough serving weight. Dough access was 60-120 minutes on days 1 and 2 and 30 minutes on all other days. X-axis indicates experimental day and THC dose provided in $\mathrm{mg}$ (per $\mathrm{kg}$ ). Black circles $=$ control dough. Gray shapes (unique per dose) and dashed vertical lines $=$ THC dough. Black boxes in (C/D) indicate a difference in THC dose provided between subjects. 

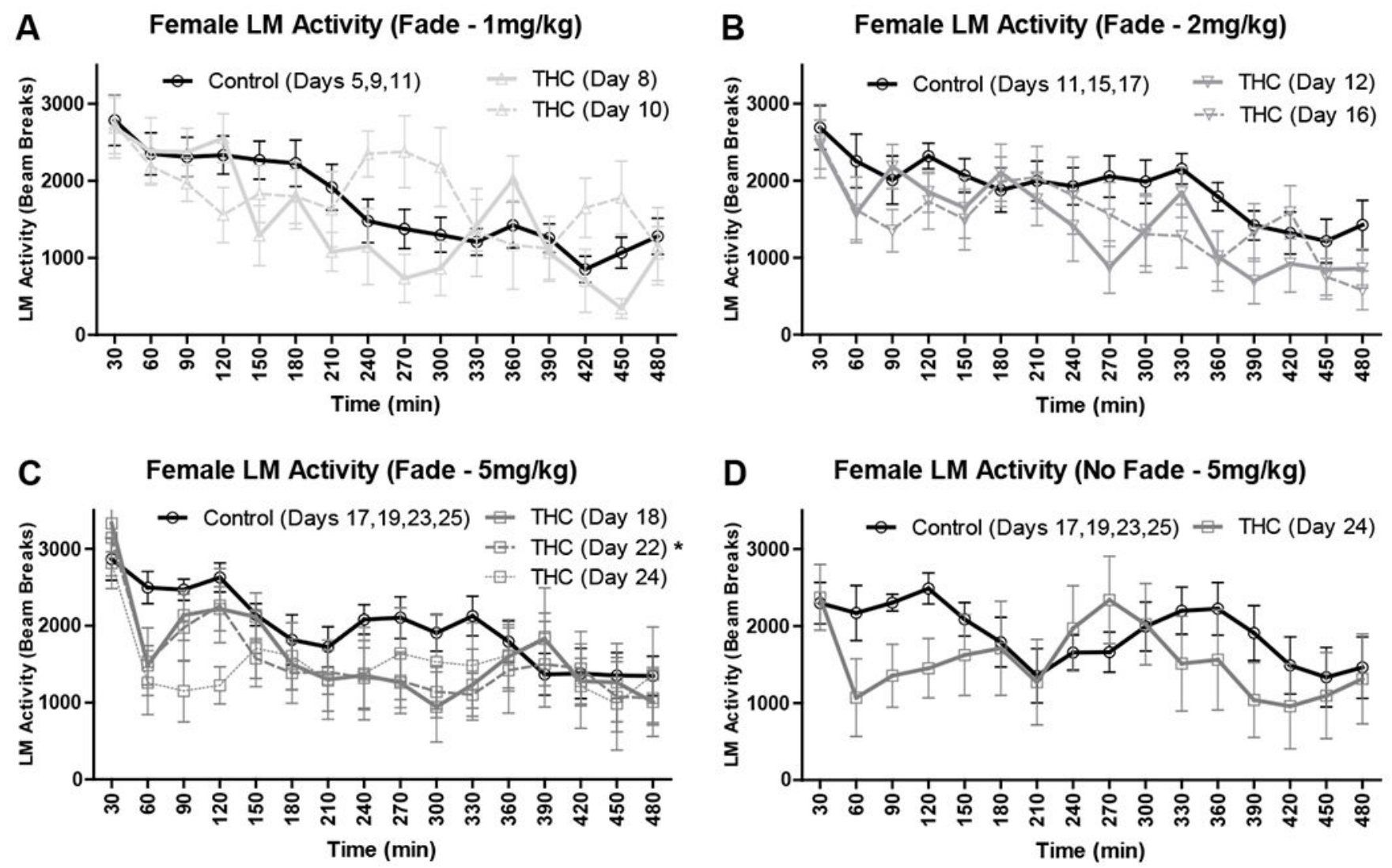

Figure 3.

Locomotor (LM) activity for all female mice (mean \pm SEM; n's $=8$ ) in 30-minute bins for the first 8 hours post-consumption for Experiment 1. LM activity is shown as the daily mean of mice for THC dough as compared to a single average of the daily means of mice on proximal days for control dough. A/B/C) Locomotor activity for female mice in Experiment 1 Fade condition at 1, 2, and $5 \mathrm{mg} / \mathrm{kg}$ THC doses. D) Locomotor activity for female mice in Experiment 1 No Fade condition at $5 \mathrm{mg} / \mathrm{kg}$ THC. ${ }^{*} p<.05$ vs control. 
A

Male LM Activity (Fade $-1 \mathrm{mg} / \mathrm{kg}$ )

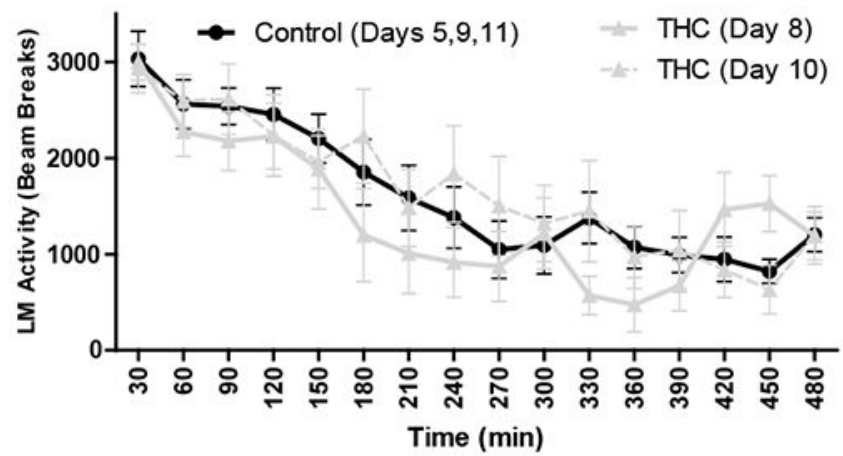

C

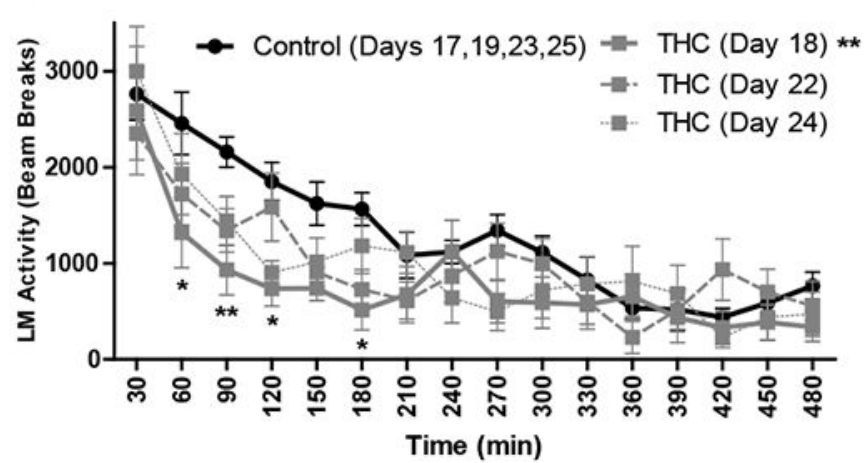

B Male LM Activity (Fade - $2 \mathrm{mg} / \mathbf{k g}$ )

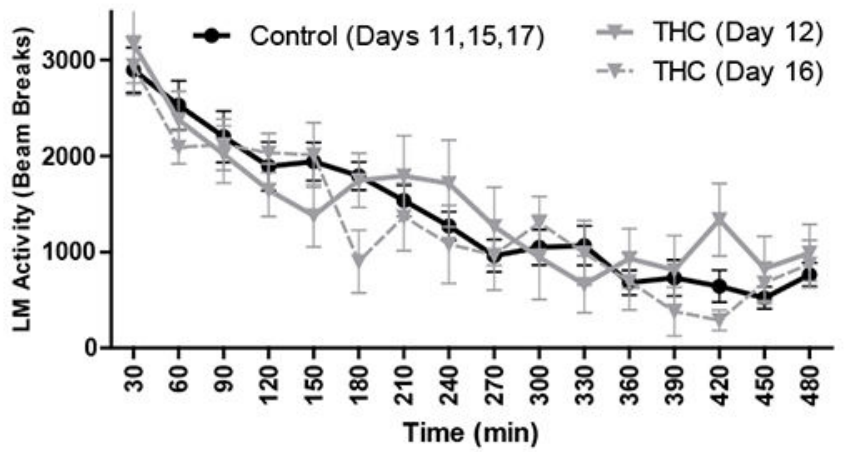

D Male LM Activity (No Fade $-5 \mathrm{mg} / \mathrm{kg}$ )

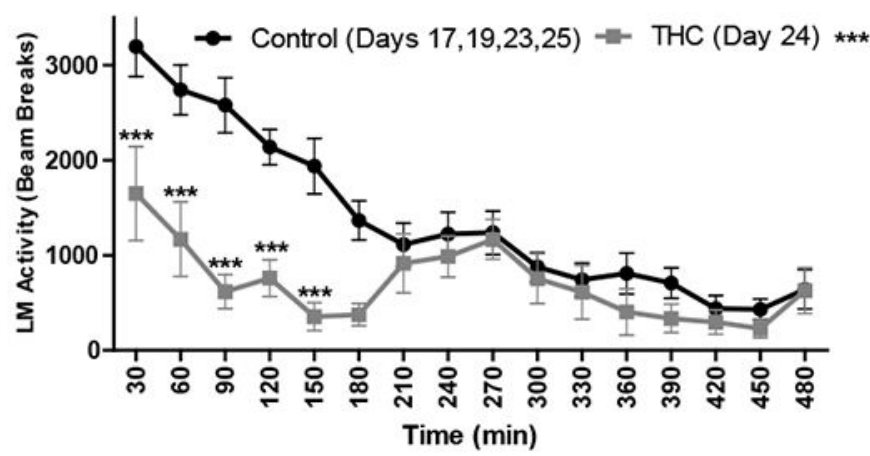

Figure 4.

Locomotor $(\mathrm{LM})$ activity for all male mice (mean $\pm \mathrm{SEM}$; n's $=8$ ) in 30-minute bins for the first 8 hours post-consumption for Experiment 1. LM activity is shown as the daily mean of mice for THC dough as compared to a single average of the daily means of mice on proximal days for control dough. A/B/C) Locomotor activity for male mice in Experiment 1 Fade condition at 1,2 , and $5 \mathrm{mg} / \mathrm{kg}$ THC doses. D) Locomotor activity for male mice in Experiment 1 No Fade condition at $5 \mathrm{mg} / \mathrm{kg}$ THC. ${ }^{*} p<.05, * * p<.01, * * * p<.001 \mathrm{vs}$ control. 
A Relative LM Activity (Fade - 1mg/kg)

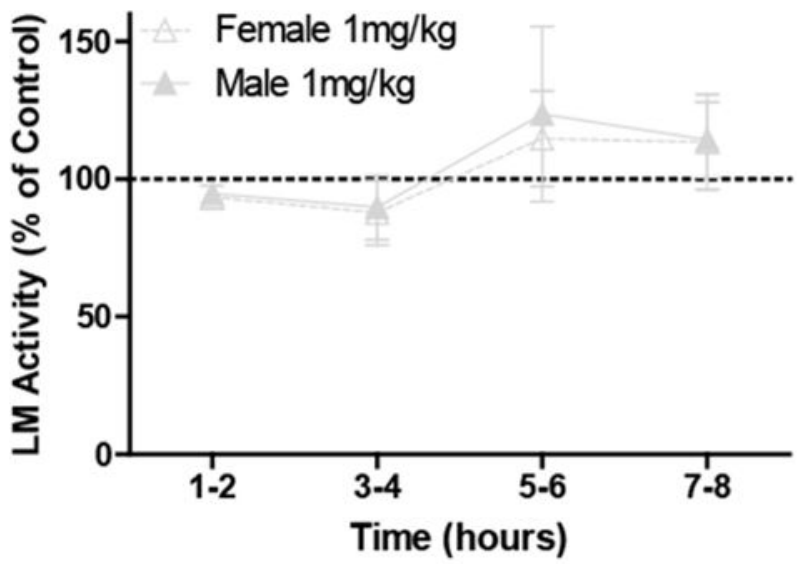

C Relative LM Activity (Fade $\mathbf{- 5 m g} / \mathbf{k g}$ )

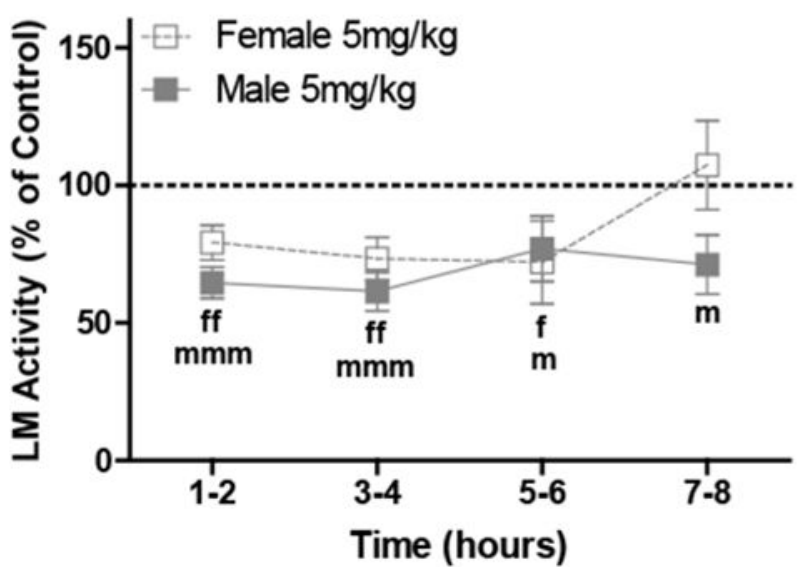

B Relative LM Activity (Fade - 2mg/kg)

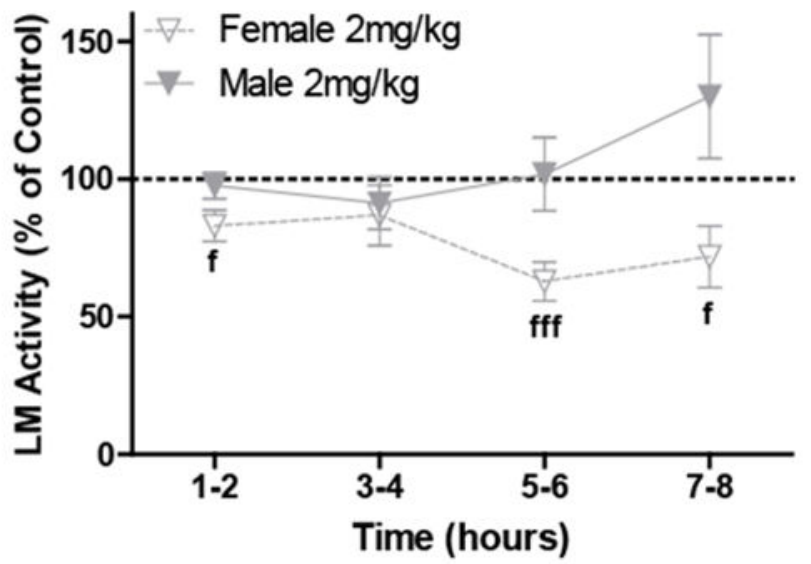

D Relative LM Activity (No Fade $\mathbf{- 5 m g} / \mathbf{k g}$ )

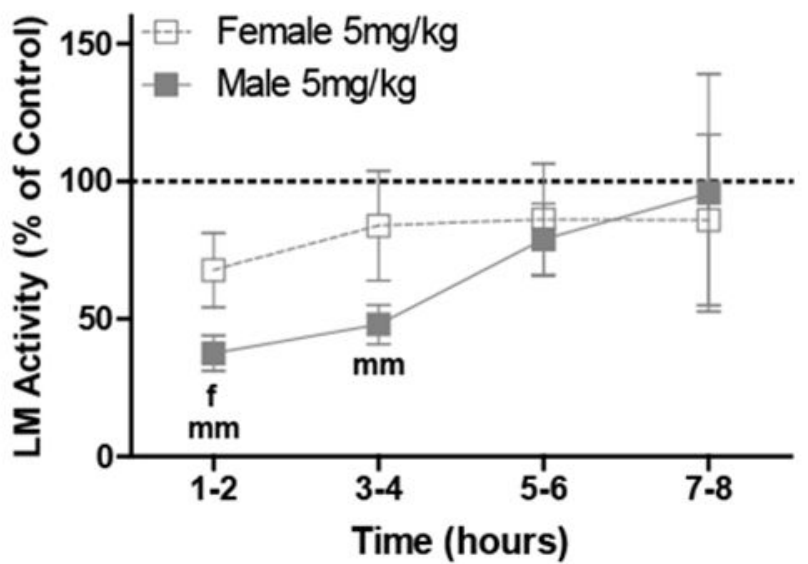

Figure 5.

Relative locomotor (LM) activity for female and male mice (mean \pm SEM; n's = 7-22) in 2hour bins post-consumption for Experiment 1. LM activity is included for each instance a mouse consumed $250 \%$ of the THC dose provided and is shown as the mean $\%$ of a single average of the daily means of these mice on proximal days for control dough. Relative LM activity for mice in the Fade condition at A) $1 \mathrm{mg} / \mathrm{kg}$, B) $2 \mathrm{mg} / \mathrm{kg}$, and C) $5 \mathrm{mg} / \mathrm{kg}$ edible THC doses provided, and D) for mice in the No Fade condition at a $5 \mathrm{mg} / \mathrm{kg}$ edible THC dose provided. ${ }^{\mathbf{f}} p<.05,{ }^{\mathbf{f f}} p<.01,{ }^{\mathbf{f f}} p<.001$ vs $100 \%$ (female), and ${ }^{\mathbf{m}} p<.05,{ }^{\mathbf{m m}} p<.01$, $\mathbf{m m m}_{p}<.001$ vs $100 \%$ (male). 

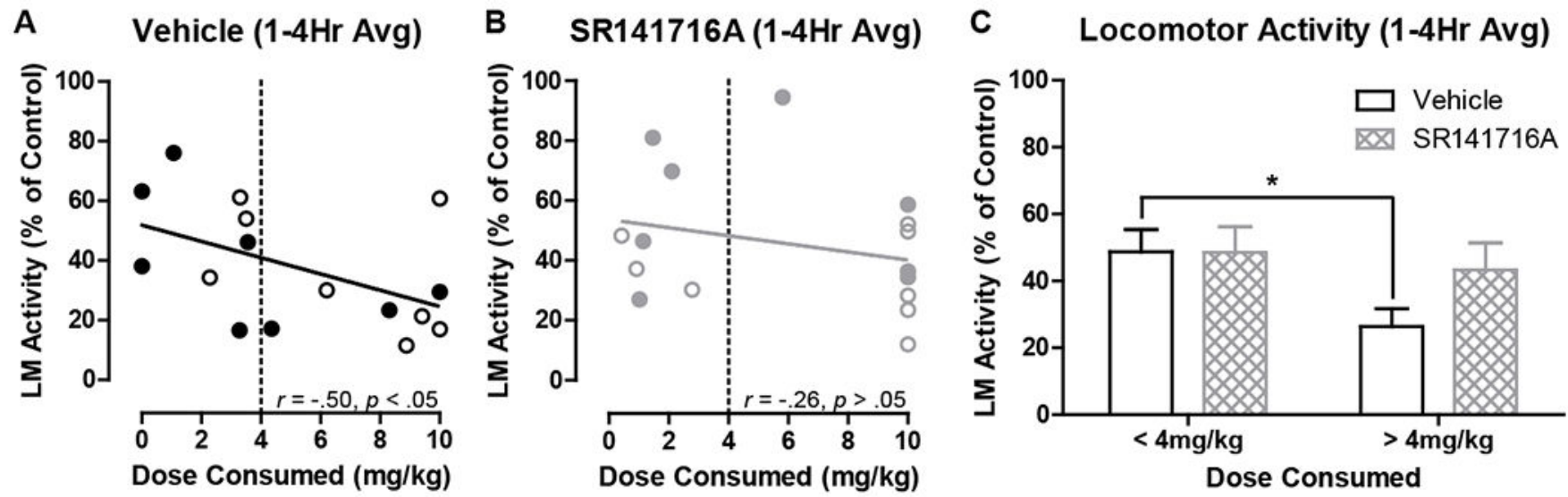

Figure 6.

Relative locomotor (LM) activity for all mice on day 33 of Experiment 1 for the first 4 hours following $10 \mathrm{mg} / \mathrm{kg}$ edible THC with SR141716A (10 mg/kg) or vehicle post-treatment. A) Association between THC dose consumed and relative locomotor activity following vehicle injection or B) following SR141716A injection (open = female; closed = male). C) Relative locomotor activity of low- (THC $<4 \mathrm{mg} / \mathrm{kg}$ ) and high- (THC $>4 \mathrm{mg} / \mathrm{kg}$ ) consuming mice following SR141716A (10 mg/kg) or vehicle post-treatment (mean \pm SEM; n’s = 7-9), ${ }^{*} p$ $<.05$ vs low-consuming.

Drug Alcohol Depend. Author manuscript; available in PMC 2020 June 01. 

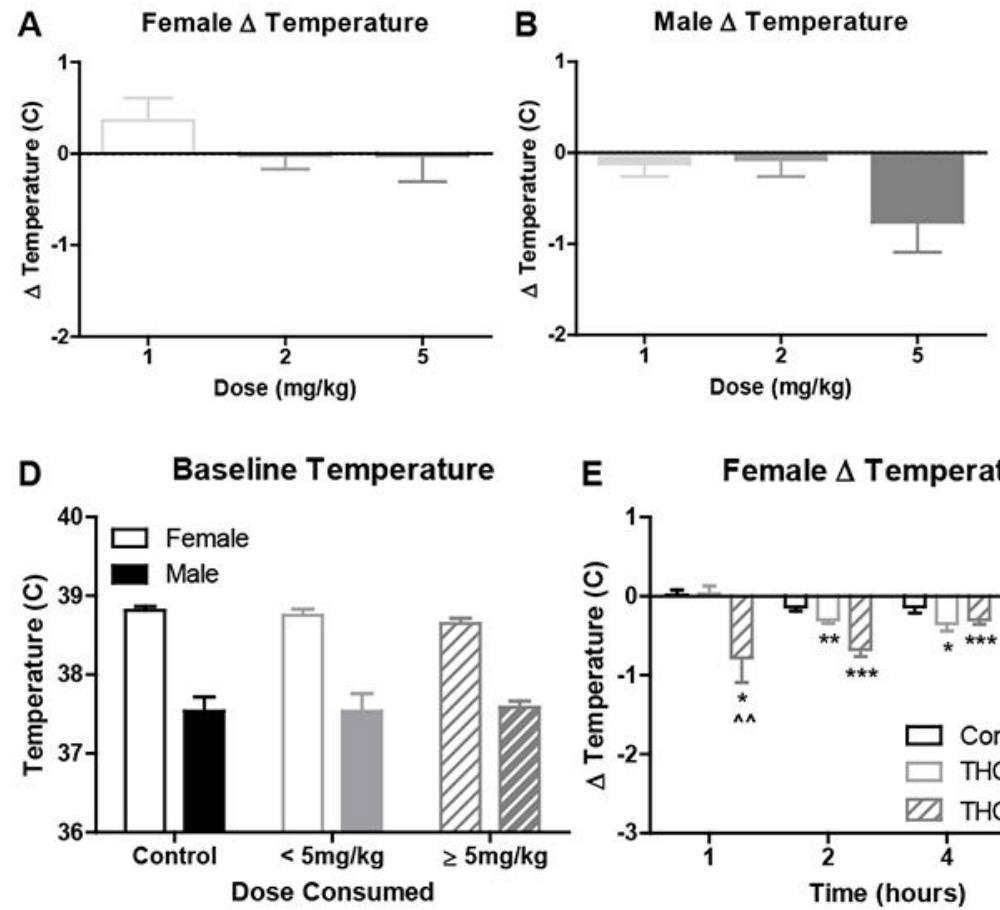
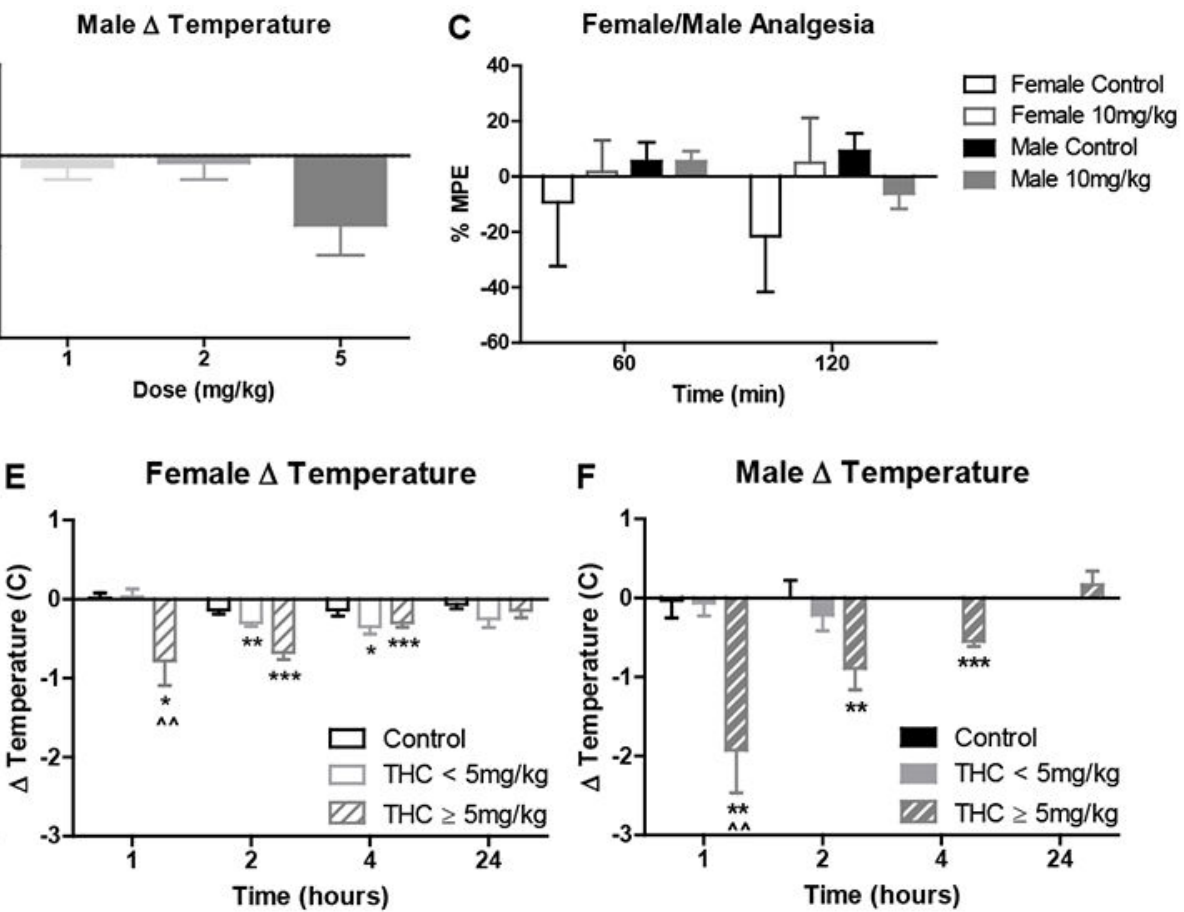

Figure 7.

A/B) Body temperature and C) analgesia for all mice following repeated THC consumption in Experiment 2 (mean \pm SEM). Average change in body temperature following control dough consumption in $\mathrm{A}$ ) female or B) male mice in the Fade condition provided 1, 2, and 5 $\mathrm{mg} / \mathrm{kg}$ THC doses (n's = 8). C) \% MPE across days 31-32 in mice in the Fade condition at 60 and 120 minutes following $10 \mathrm{mg} / \mathrm{kg}$ THC or control dough access (n's =4). D/E/F) Body temperature for all mice following acute THC consumption in Experiment 3 (mean \pm SEM). D) Day 8 baseline body temperature following control dough consumption, grouped by THC dose consumed the following day, and day 9 change in body temperature in control, low- (THC $<5 \mathrm{mg} / \mathrm{kg}$ ), and high- (THC $\geq 5 \mathrm{mg} / \mathrm{kg}$ ) consuming E) female or F) male mice in the No Fade condition (n's $=6-12$ ). ${ }^{\wedge \wedge} p<.01$ vs control; $* p<.05, * * p<.01,{ }^{*} * * p<.001$ vs $0^{\circ} \mathrm{C}$. 
Table 1

Percent of Dough Consumed

\begin{tabular}{|c|c|c|c|c|c|c|c|c|}
\hline Experiment & Sex & Condition & Dose & $\mathbf{N}$ & Median & $\mathbf{W}$ & $\mathbf{p}$ & \\
\hline \multirow[t]{14}{*}{1} & Female & Fade & Control & 8 & 98.95 & -15 & .0625 & \\
\hline & & & $1 \mathrm{mg} / \mathrm{kg}$ & 8 & 94.95 & -10 & .1250 & \\
\hline & & & $2 \mathrm{mg} / \mathrm{kg}$ & 8 & 100.00 & -6 & .2500 & \\
\hline & & & $5 \mathrm{mg} / \mathrm{kg}$ & 8 & 90.05 & -21 & .0313 & $*$ \\
\hline & & & $10 \mathrm{mg} / \mathrm{kg}$ & 8 & 81.05 & -10 & .1250 & \\
\hline & & No Fade & Control & 8 & 98.60 & -10 & .1250 & \\
\hline & & & $5 \mathrm{mg} / \mathrm{kg}$ & 8 & 100.00 & - & - & \\
\hline & Male & Fade & Control & 8 & 100.00 & -3 & .5000 & \\
\hline & & & $1 \mathrm{mg} / \mathrm{kg}$ & 8 & 100.00 & -1 & 1.0000 & \\
\hline & & & $2 \mathrm{mg} / \mathrm{kg}$ & 8 & 100.00 & - & - & \\
\hline & & & $5 \mathrm{mg} / \mathrm{kg}$ & 8 & 84.40 & -21 & .0313 & * \\
\hline & & & $10 \mathrm{mg} / \mathrm{kg}$ & 8 & 39.60 & -28 & .0156 & * \\
\hline & & No Fade & Control & 8 & 100.00 & -6 & .2500 & \\
\hline & & & $5 \mathrm{mg} / \mathrm{kg}$ & 8 & 100.00 & - & - & \\
\hline \multirow[t]{8}{*}{2} & Female & Fade & Control & 8 & 100.00 & -3 & .5000 & \\
\hline & & & $1 \mathrm{mg} / \mathrm{kg}$ & 8 & 79.55 & -15 & .0625 & \\
\hline & & & $2 \mathrm{mg} / \mathrm{kg}$ & 8 & 96.20 & -10 & .1250 & \\
\hline & & & $5 \mathrm{mg} / \mathrm{kg}$ & 8 & 87.55 & -10 & .1250 & \\
\hline & Male & Fade & Control & 8 & 100.00 & -6 & .2500 & \\
\hline & & & $1 \mathrm{mg} / \mathrm{kg}$ & 8 & 100.00 & -6 & .1736 & \\
\hline & & & $2 \mathrm{mg} / \mathrm{kg}$ & 8 & 100.00 & - & - & \\
\hline & & & $5 \mathrm{mg} / \mathrm{kg}$ & 8 & 85.00 & -15 & .0579 & \\
\hline \multirow[t]{6}{*}{3} & Female & No Fade & Control & 6 & 95.01 & -136 & .0005 & $* * *$ \\
\hline & & & $5 \mathrm{mg} / \mathrm{kg}$ & 6 & 81.67 & -6 & .2500 & \\
\hline & & & $10 \mathrm{mg} / \mathrm{kg}$ & 12 & 61.32 & -45 & .0039 & $* *$ \\
\hline & Male & No Fade & Control & 6 & 100.00 & -1 & 1.0000 & \\
\hline & & & $5 \mathrm{mg} / \mathrm{kg}$ & 6 & 92.02 & -10 & .1250 & \\
\hline & & & $10 \mathrm{mg} / \mathrm{kg}$ & 12 & 58.93 & -66 & .0010 & $* *$ \\
\hline$p<.05$ & & & & & & & & \\
\hline$* *{ }^{*} p .01$ & & & & & & & & \\
\hline$* * * * 0.001 \mathrm{vs}$ & & & & & & & & \\
\hline
\end{tabular}

Drug Alcohol Depend. Author manuscript; available in PMC 2020 June 01. 


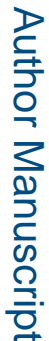

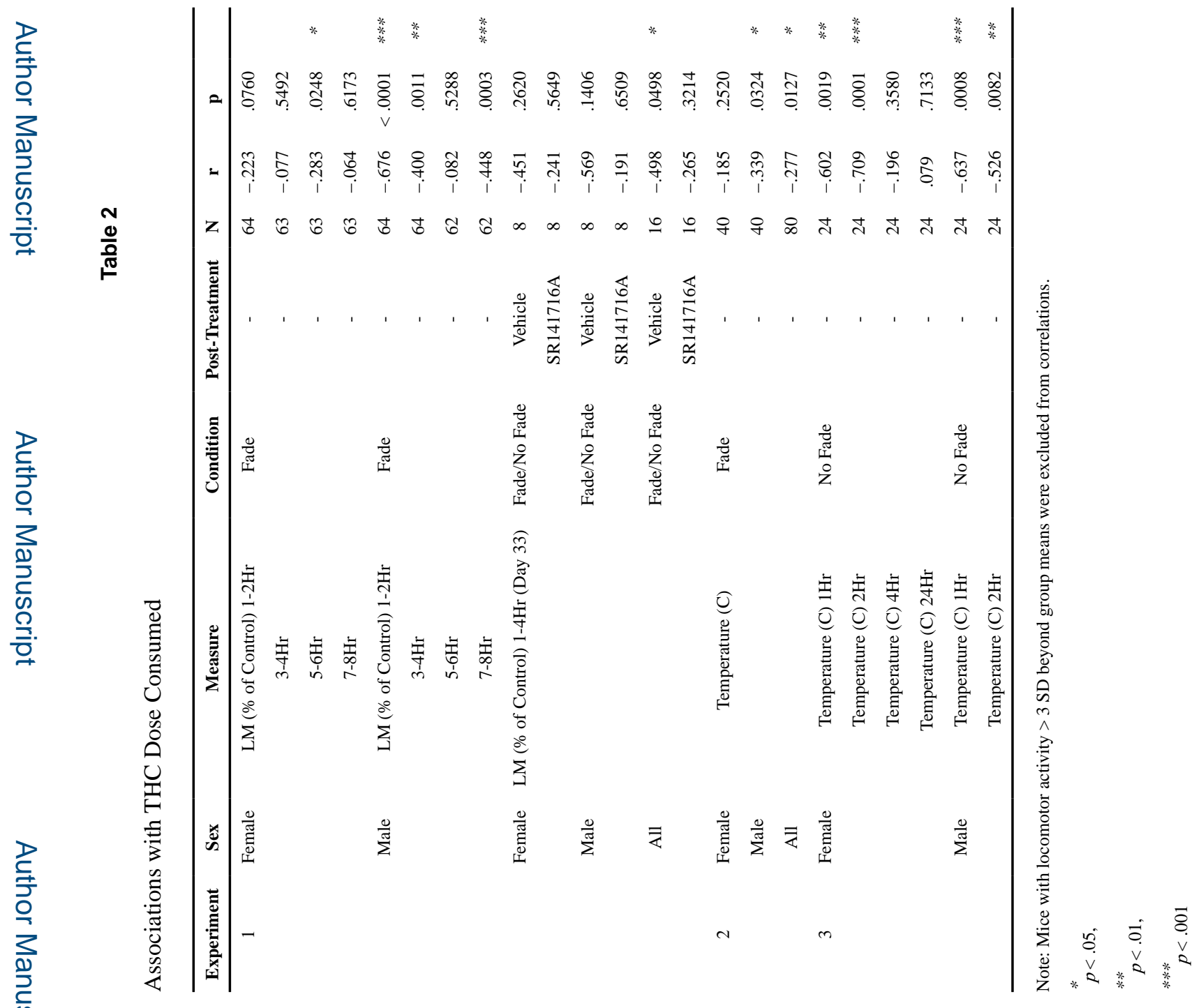

Drug Alcohol Depend. Author manuscript; available in PMC 2020 June 01. 